\title{
A multi-center cardiovascular magnetic resonance network for tele-training, tele-supervision and knowledge sharing
}

Fabian Muehlberg ${ }^{1 *}$, Florian von Knobelsdorff-Brenkenhoff $^{1}$, Daniel Neumann², Julius Traber $^{1}$, Nils Alwardt ${ }^{2}$, Jeanette Schulz-Menger ${ }^{1}$

From 18th Annual SCMR Scientific Sessions

Nice, France. 4-7 February 2015

\section{Background}

Training of cardiovascular magnetic resonance (CMR) is an important topic in times of growing acceptance of the method for accurate diagnosis and management of cardiovascular disease. However, off-site trainings are becoming less acceptable with increasing cost and time pressure. Here we introduce a novel CMR network, capable of partially remote CMR training and continuous remote expert support.

\section{Methods}

Conceptual, technical and content-related characteristics of our teaching methods are introduced. 97 participants of traditional fellowship CMR teaching and the novel

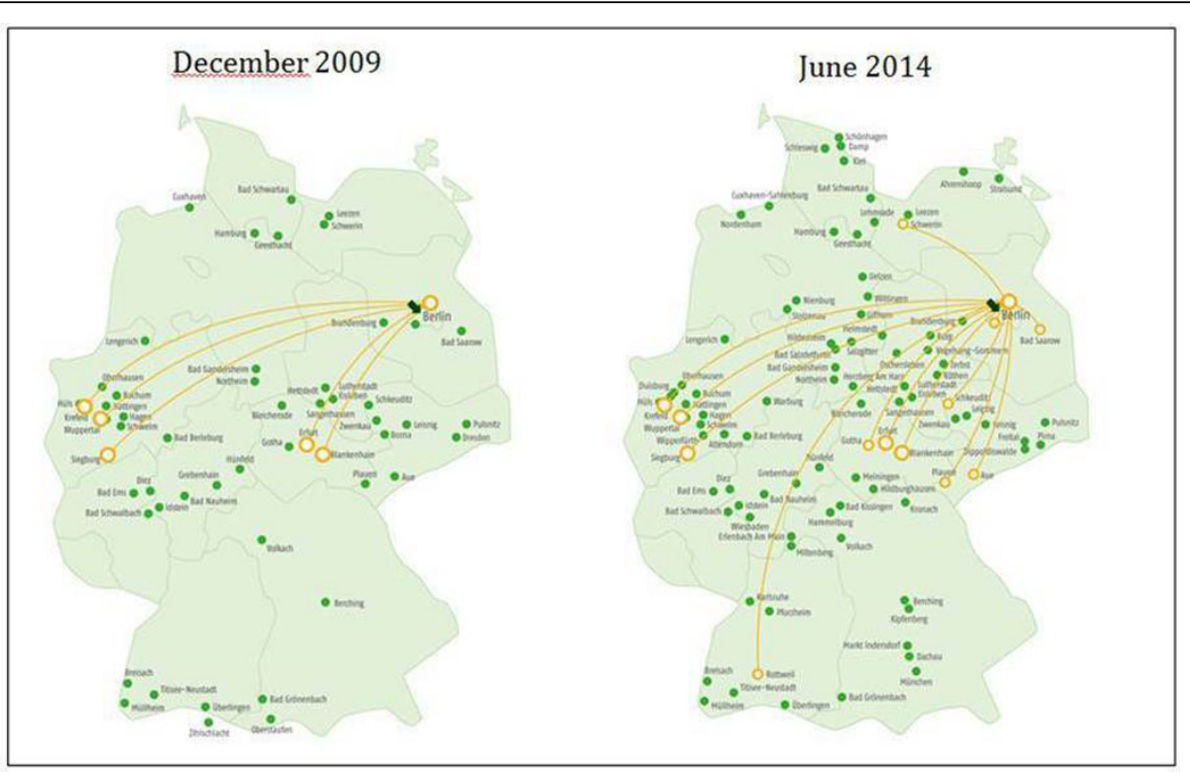

Figure 1 CMR network expansion between December 2009 and June 2014.

'ECRC, Charité University Medicine Berlin and HELIOS Clinics, Berlin, Germany

Full list of author information is available at the end of the article

(C) 2015 Muehlberg et al; licensee BioMed Central Ltd. This is an Open Access article distributed under the terms of the Creative Commons Attribution License (http://creativecommons.org/licenses/by/4.0), which permits unrestricted use, distribution, and 


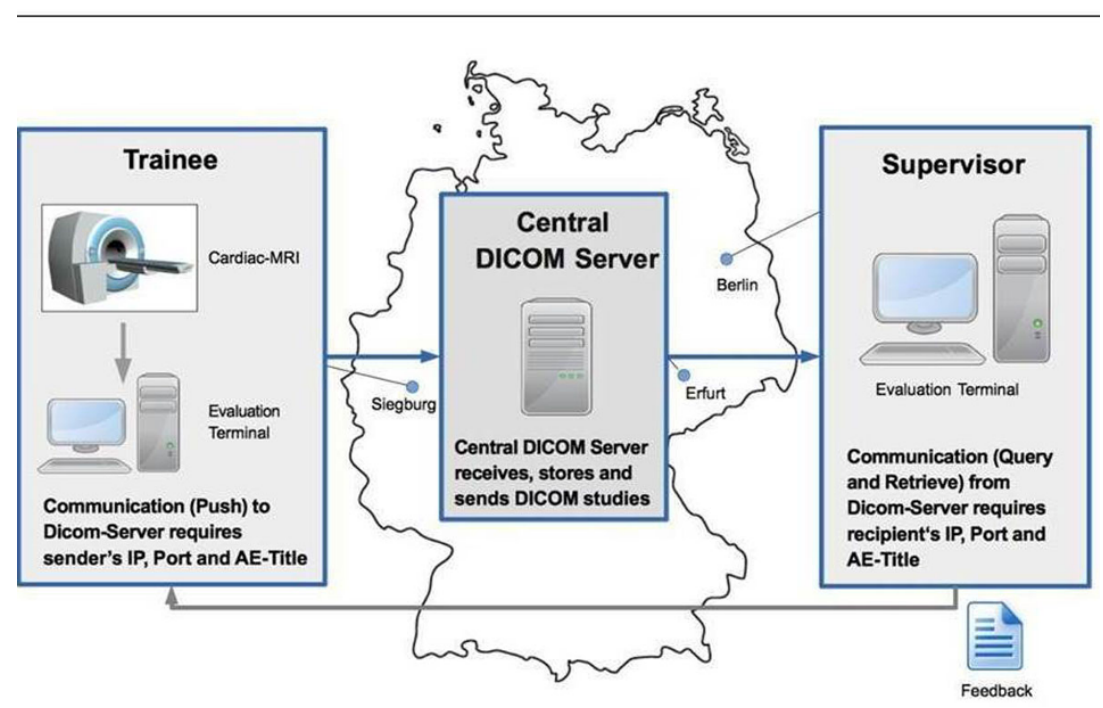

Figure 2 Illustration of the CMR network architecture.

module-based network teaching were surveyed to assess their CMR performance.

\section{Results}

The number of hospitals in our CMR network increased from 5 in 2009 to 14 in 2014. $79 \%$ of network hospitals conducted more than 100 CMR scans annually. (Fig. 1) Among these network hospitals are four small institutions ( $<400$ beds) and five medium-sized hospitals (400-1000 beds). Network teaching reduced off-site CMR training to only five weeks. The time to first selfconducted CMR scans was one week in network teaching but more than one month for $32 \%$ of participants in traditional CMR teaching. The CMR network enables experts from distant locations to supervise and control CMR scans in a distant hospital in real-time. (Fig. 2)

\section{Conclusions}

A CMR network can be built with reasonable amount of technical and man power-related resources. It provides an efficient teaching platform with minimum off-site time for trainees. Real-time remote supervision and scan control capabilities support the decentralization of CMR expertise and enable even small and rurally located institutions to offer CMR scans at high-quality level.

\section{Authors' details}

'ECRC, Charité University Medicine Berlin and HELIOS Clinics, Berlin, Germany. ${ }^{2}$ Helios IT Services GmbH, Berlin, Germany.

Published: 3 February 2015
doi:10.1186/1532-429X-17-S1-P228

Cite this article as: Muehlberg et al:: A multi-center cardiovascular magnetic resonance network for tele-training, tele-supervision and knowledge sharing. Journal of Cardiovascular Magnetic Resonance 201517 (Suppl 1):P228.
Submit your next manuscript to BioMed Central and take full advantage of:

- Convenient online submission

- Thorough peer review

- No space constraints or color figure charges

- Immediate publication on acceptance

- Inclusion in PubMed, CAS, Scopus and Google Scholar

- Research which is freely available for redistribution

Submit your manuscript at www.biomedcentral.com/submit
C Biomed Central 